\title{
Lactobacillus helveticus SBT2171, a cheese starter, regulates proliferation and cytokine production of immune cells
}

\author{
M. Yamashita, K. Ukibe, H. Uenishi, T. Hosoya, F. Sakai, and Y. Kadooka ${ }^{1}$ \\ Milk Science Research Institute, Megmilk Snow Brand Co. Ltd., 1-1-2 Minamidai, Kawagoe, Saitama, 350-1165, Japan
}

\begin{abstract}
Consumption of a Lactobacillus helveticus SBT2171 (LH2171)-containing cheese has been reported to exhibit immunoregulatory actions, including an increase in regulatory $\mathrm{T}$ cell population and reduction in proinflammatory cytokine production in mice. We examined the in vitro effects of LH2171 cells per se on immune cell function, specifically proliferation and cytokine production, which are primary reactions of the immune response. Immune cell fractions were prepared by mechanical disruption of mesenteric lymph nodes (MLN), Peyer's patches (PP), and spleens (SP) of mice. The cell fractions were dispensed into a culture plate and stimulated with anti-CD3/CD28 antibody beads in place of antigen-presenting cells or lipopolysaccharide (LPS) in the presence or absence of heat-treated LH2171 cells and other bacterial strains for comparison. After incubation, proliferation, cytokine production, and cell viability of the immune cells were determined. The LH2171 significantly inhibited the proliferation of MLN immune cells stimulated with anti-CD3/CD28 compared with other bacterial strains. The antiproliferative potency of LH2171 was effective not only on MLN but also on PP and SP stimulated with anti-CD3/CD28 or LPS. The LH2171 also decreased LPS-stimulated IL-6 production from MLN, PP, and SP, and IL-1 $\beta$ production from SP, but LH2171 did not affect the viability of immune cells. The LH2171 inhibited immune cell proliferation and proinflammatory cytokine (IL-6 and IL-1 $\beta$ ) production. The inhibitory actions were not due to cytotoxicity to immune cells, suggesting that LH2171 is a dairy Lactobacillus strain with beneficial immunoregulatory properties.
\end{abstract}

Key words: Lactobacillus helveticus, immune cell, proliferation, cytokine production

Received February 11, 2014.

Accepted April 22, 2014.

${ }^{1}$ Corresponding author: y-kadooka@meg-snow.com

\section{INTRODUCTION}

Lactobacillus helveticus SBT2171 (LH2171) has high protease activity (Tan et al., 1995) and has been used as a starter bacterial strain in the production of a Gouda-type cheese, and we recently reported that consumption of cheese containing LH2171 led to immunoregulatory actions, including induction of regulatory $\mathrm{T}$ cells, reduction in proinflammatory cytokine production, and alleviation of dextran sulfate sodium-induced colitis in mice (Hosoya et al., 2012). Other studies have also reported immunomodulatory effects due to cheese consumption in humans (Ibrahim et al., 2010) and rats (Lollo et al., 2012); however, the studies did not examine whether the starter bacterial cells used in the cheese production could induce immunomodulatory functions. Although it is not clear which components of cheese are responsible for the modulatory actions, we consider lactic acid bacteria (LAB) a possibility.

The immunomodulatory actions of LAB can be applied not only to activate immune responses to external invasion and tumors, but also to regulate excessive immune responses involved in certain abnormalities, including inflammatory bowel disease (IBD) and rheumatoid arthritis (RA), for example. An approach to ameliorate such excess responses involves using the immunoregulatory functions of LAB. Such regulatory functions include actions of LAB on immune cells, such as inducing apoptosis of antigen-stimulated immune cells (Kanzato et al., 2008) and suppressing immune cell proliferation (Peluso et al., 2007; Yoshida et al., 2011). Lactic acid bacteria have also been shown to prevent proinflammatory cytokine production (Matsumoto et al., 2005; Lee et al., 2008; Philippe et al., 2011), an excess production of which could cause inflammatory and autoimmune diseases (Atreya et al., 2000; Yamamoto et al., 2000).

The present study focused on the immunoregulatory actions of LH2171 on the basis of our previous study, which showed the immunoregulatory actions of cheese containing LH2171 and suggested a possible contribution of LH2171 itself to the regulatory function. Thus, we examined the effects of LH2171 bacterial cells on mouse immune cells treated in vitro with immune cell 
stimulants, an anti-CD3/CD28 antibody, and LPS, by measuring proliferation and inflammatory cytokine production.

\section{MATERIALS AND METHODS}

\section{Mice}

Male C57BL/6J mice (5 to 6 wk old) were purchased from Charles River Japan Inc. (Yokohama, Japan) and acclimatized for more than $1 \mathrm{wk}$ with free access to pellet food (CE-2; Clea Japan Inc., Tokyo, Japan) and water. Mice were maintained under controlled conditions of temperature, humidity, and light $\left(23 \pm 2^{\circ} \mathrm{C}\right.$ temperature, $50 \pm 10 \%$ humidity, and 12-h light-dark cycle). Experiments were carried out in accordance with NRC (1996) guidelines.

\section{Preparation of Immune Cells}

Mice were killed and dissected under anesthesia at 7 to 10 wk of age. Mesenteric lymph nodes (MLN), Peyer's patches (PP), and spleens (SP) of mice were mechanically disrupted in a cell culture medium (RPMI 1640 medium) containing $10 \%$ heat-inactivated fetal bovine serum, $10 \mathrm{~m} M$ HEPES buffer, $2 \mathrm{~m} M$ L-glutamine, $100 \mathrm{U}$ of penicillin/mL, $100 \mu \mathrm{g}$ of streptomycin/ $\mathrm{mL}$, and $0.05 \mathrm{mM} 2$-mercaptoethanol. Cell suspensions thus prepared were filtered through $70-\mu \mathrm{m}$ cell strainers (BD Biosciences, San Jose, CA). Erythrocytes remaining in the spleen cell preparation were eliminated by density-gradient centrifugation with Lympholyte-M medium (Cedarlane Laboratories Ltd., Burlington, Ontario, Canada) according to the manufacturer's protocol. Cells were washed twice, resuspended in the cell culture medium, and stored on ice until the start of the cell culture experiments.

\section{Preparation of Bacterial Cells}

A total of 41 LAB strains used in this study, which originated from dairy products and the human intestine, are shown in Table 1. Streptococcus thermophilus and Lactobacillus strains were grown at $37^{\circ} \mathrm{C}$, and Lactobacillus kefiranofaciens, Lactobacillus plantarum, and Lactococcus lactis were grown at $30^{\circ} \mathrm{C}$ for $16 \mathrm{~h}$ in de Man, Rogosa, and Sharpe (MRS) medium (Difco Laboratories Inc., Detroit, MI). Bifidobacterium strains were grown at $37^{\circ} \mathrm{C}$ and Leuconostoc strains were grown at $30^{\circ} \mathrm{C}$ for $16 \mathrm{~h}$ in GAM medium (Nissui Seiyaku Co., Tokyo, Japan) supplemented with $1 \%$ glucose. The incubation was carried out in stationary culture. Cells of LAB harvested by centrifugation at $8,500 \times g$ for
$10 \mathrm{~min}$ at $4^{\circ} \mathrm{C}$ were washed twice with distilled water, and then lyophilized. Lyophilized bacterial cells were resuspended in distilled water at $10 \mathrm{mg} / \mathrm{mL}$ and heat treated at $80^{\circ} \mathrm{C}$ for $30 \mathrm{~min}$.

\section{Cell Proliferation Assay}

Immune cells isolated from mice $\left(5 \times 10^{4}\right.$ cells/ well) were stimulated with anti-CD3/CD28 antibody beads (Life Technologies Inc., Gaithersburg, MD; $5 \times$ $10^{4}$ beads/well) or LPS from Escherichia coli (SigmaAldrich Japan, Tokyo, Japan; $10 \mu \mathrm{g} / \mathrm{mL}$ ) in the presence or absence of heat-treated LAB $(10 \mu \mathrm{g} / \mathrm{mL})$ in 96-well round-bottomed plates (Asahi Glass Co. Ltd., Yokohama, Japan) at $37^{\circ} \mathrm{C}$ for $3 \mathrm{~d}$ in $5 \% \mathrm{CO}_{2}$ in air. After stimulation, PrestoBlue Cell Viability Reagent (Life Technologies Inc.), which becomes highly fluorescent depending on the proliferation of cells, was added to each well according to the manufacturer's protocol, and incubated for about $7 \mathrm{~h}$. After incubation, the fluorescence intensity (excitation: $530 \mathrm{~nm}$; emission: $580 \mathrm{~nm}$ ) of each well was measured.

\section{Measurement of Cell Viability}

Immune cells isolated from mice $\left(5 \times 10^{4}\right.$ cells/well $)$ not stimulated with proliferative activators were cultured in the presence or absence of heat-treated LAB $(10 \mu \mathrm{g} / \mathrm{mL})$ in 96 -well round-bottomed plates at $37^{\circ} \mathrm{C}$ for $3 \mathrm{~d}$ in $5 \% \mathrm{CO}_{2}$ in air. After incubation, CyQUANT Direct Cell Proliferation Assay Kit (Life Technologies Inc.), which is an assay measuring the number of viable cells by the fluorescence intensity based on DNA content and cell membrane permeability, whose increase reflects early apoptosis and cytotoxicity, was added to each well according to the manufacturer's protocol and incubated for $1 \mathrm{~h}$. After incubation, the fluorescence intensity (excitation: $485 \mathrm{~nm}$; emission: $530 \mathrm{~nm}$ ) of each well was measured and the number of viable cells was calculated according to the manufacturer's instructions.

\section{Cytokine Analysis by ELISA}

Immune cells isolated from mice $\left(2 \times 10^{5}\right.$ cells/well $)$ were stimulated with LPS $(10 \mu \mathrm{g} / \mathrm{mL})$ in the presence or absence of heat-treated LAB $(10 \mu \mathrm{g} / \mathrm{mL})$ in 96 -well round-bottomed plates at $37^{\circ} \mathrm{C}$ for $2 \mathrm{~d}$ in $5 \% \mathrm{CO}_{2}$ in air. After stimulation, culture supernatants were collected and stored at $-30^{\circ} \mathrm{C}$ until their use in cytokine assays. Levels of IL-6, IL-1 $\beta$, and tumor necrosis factor $\alpha(\mathbf{T N F}-\boldsymbol{\alpha})$ in the supernatant were measured by ELISA according to the manufacturer's instructions (R\&D Systems, Minneapolis, MN). 
Table 1. Lactic acid bacteria (LAB) used in the present study

\begin{tabular}{|c|c|c|}
\hline No. & LAB & Strain $^{1}$ \\
\hline 1 & Lactobacillus helveticus & SBT0064 \\
\hline 2 & L. helveticus & SBT0621 \\
\hline 3 & L. helveticus & $\mathrm{JCM} 1120^{\mathrm{T}}$ \\
\hline 4 & L. helveticus & SBT2161 \\
\hline 5 & L. helveticus & SBT2171 \\
\hline 6 & Lactobacillus kefiranofaciens ssp. kefiranofaciens & $\mathrm{JCM} 6985^{\mathrm{T}}$ \\
\hline 7 & L. kefiranofaciens ssp. kefirgranum & $\mathrm{JCM} 8572^{\mathrm{T}}$ \\
\hline 8 & L. kefiranofaciens ssp. kefirgranum & SBT11088 \\
\hline 9 & L. kefiranofaciens & SBT11223 \\
\hline 10 & L. kefiranofaciens & SBT11295 \\
\hline 11 & Lactobacillus acidophilus & SBT1372 \\
\hline 12 & L. acidophilus & SBT1921 \\
\hline 13 & L. acidophilus & SBT2062 \\
\hline 14 & L. acidophilus & SBT2068 \\
\hline 15 & Lactobacillus. gasseri & $\mathrm{JCM} 1131^{\mathrm{T}}$ \\
\hline 16 & L. gasseri & JCM1025 \\
\hline 17 & L. gasseri & JCM5813 \\
\hline 18 & L. gasseri & JCM8788 \\
\hline 19 & Lactobacillus buchneri & JCM $1115^{\mathrm{T}}$ \\
\hline 20 & Lactobacillus. paracasei & NCFB151 ${ }^{\mathrm{T}}$ \\
\hline 21 & Lactobacillus plantarum & NCFB1752 $2^{\mathrm{T}}$ \\
\hline 22 & Lactobacillus delbrueckii ssp. bulgaricus & $\mathrm{JCM} 1002^{\mathrm{T}}$ \\
\hline 23 & L. delbrueckii ssp. lactis & $\mathrm{JCM} 1248^{\mathrm{T}}$ \\
\hline 24 & Lactobacillus rhamnosus & JCM1136 \\
\hline 25 & Lactobacillus zeae & $\mathrm{JCM} 11302^{\mathrm{T}}$ \\
\hline 26 & Lactobacillus crispatus & $\mathrm{JCM} 1185^{\mathrm{T}}$ \\
\hline 27 & Lactobacillus amylovorus & JCM1126 $6^{\mathrm{T}}$ \\
\hline 28 & Lactobacillus johnsonii & $\mathrm{JCM} 2010^{\mathrm{T}}$ \\
\hline 29 & Lactobacillus reuteri & JCM1112 \\
\hline 30 & Lactobacillus fermentum & $\mathrm{JCM}_{1173^{\mathrm{T}}}$ \\
\hline 31 & Lactococcus lactis ssp. cremoris & $\mathrm{JCM} 16167^{\mathrm{T}}$ \\
\hline 32 & L. lactis ssp. lactis & $\mathrm{JCM} 5805^{\mathrm{T}}$ \\
\hline 33 & Bifidobacterium longum & SBT2497 \\
\hline 34 & B. longum & SBT10841 \\
\hline 35 & Bifidobacterium infantis & SBT10258 \\
\hline 36 & Bifidobacterium breve & SBT10522 \\
\hline 37 & Bifidobacterium animalis & ATCC $25527^{\mathrm{T}}$ \\
\hline 38 & Bifidobacterium adolescentis & SBT10830 \\
\hline 39 & Leuconostoc mesenteroides ssp. mesenteroides & $\mathrm{JCM} 6124^{\mathrm{T}}$ \\
\hline 40 & Leuconostoc pseudomesenteroides & JCM9696 \\
\hline 41 & Streptococcus thermophilus & ATCC $19258^{\mathrm{T}}$ \\
\hline
\end{tabular}

\section{Statistical Analysis}

The 1-sample $t$-test was used to evaluate the difference between proliferation indices each LAB strain exhibited and the control value of 100 that was set as a proliferation index in the absence of LAB. The Tukey-Kramer test was used for multiple comparisons between the groups. A $P$-value less than 0.05 was considered statistically significant. Data were analyzed using StatView software (version 5.0; SAS Institute Inc., Cary, NC).

\section{RESULTS}

\section{LH2171 Suppressed the Proliferation of Immune Cells}

We first examined the proliferative response of immune cells using MLN cells stimulated with anti-
CD3/CD28 antibody beads in the presence or absence of heat-treated LH2171 bacterial cells and 40 other LAB strains (Table 1). Figure 1 shows that 16 out of 41 strains significantly suppressed the proliferation of MLN cells compared with the control containing no LAB cells. The 16 strains demonstrating suppressive activity were Lactobacillus helveticus (5 strains, including LH2171; from raw milk, fermented milk, and cheese), Lactobacillus acidophilus (4 strains, from the human intestine and fermented milk), Lactobacillus kefiranofaciens (4 strains, from fermented milk and raw milk), and 3 other strains from different species (Lactobacillus gasseri, Lactobacillus delbrueckii, and Lactobacillus paracasei from the human intestine, fermented milk, and a commercial milk product, respectively). 


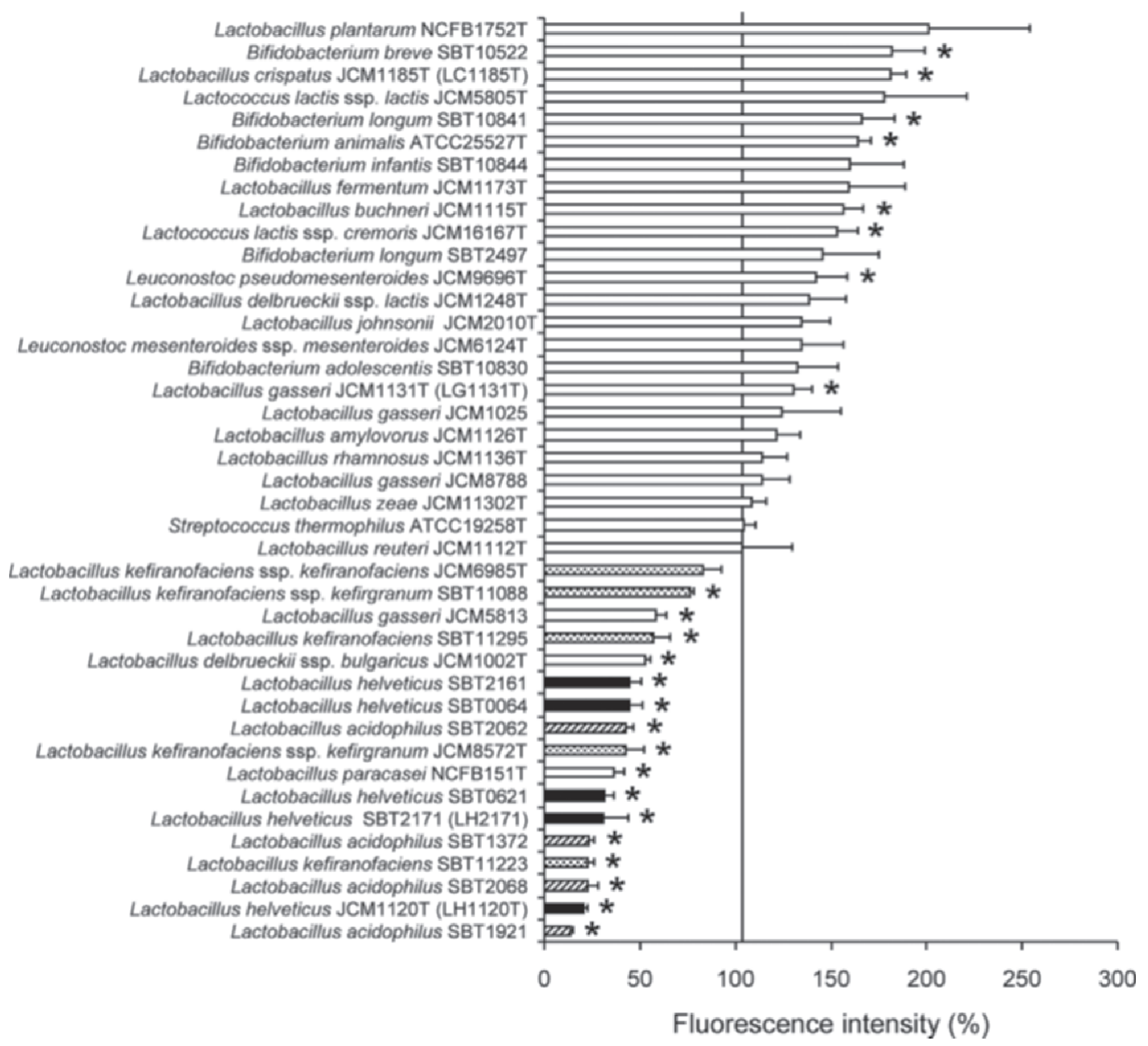

Figure 1. Effect of heat-treated lactic acid bacteria (LAB) on the proliferation of mesenteric lymph node cells stimulated with anti-CD3/ CD28 antibody beads. Proliferation was represented as fluorescence intensity (\%), in which the control value obtained by the anti-CD3/CD28 stimulation alone was set to $100 \%$. Data are shown as means $\pm \mathrm{SD}(\mathrm{n}=3)$. Asterisks indicate a significant difference $(P<0.05 ; 1$-sample $t$ test) from the control. The top 3 LAB species in terms of the number of strains that showed a significant suppression are marked as follows: Lactobacillus helveticus (solid black bars), Lactobacillus acidophilus (striped bars), and Lactobacillus kefiranofaciens (dotted bars).

We further compared the proliferative responses among MLN, PP, and SP cells stimulated with anti-CD3/CD28 or LPS in the presence or absence of LH2171 as well as 3 other LAB strains for comparison: L. gasseri $\mathrm{JCM}_{1131^{\mathrm{T}}}\left(\mathbf{L G} \mathbf{1 1 3 1} \mathbf{1}^{\mathrm{T}}\right)$, a strain with no suppression of immune cell proliferation, according to Figure 1, and close taxonomical proximity to L. helveticus, according to the analysis of their 16s rRNA; Lactobacillus crispatus $\mathrm{JCM}_{1185^{\mathrm{T}}}\left(\mathbf{L} \mathbf{C} \mathbf{1 1 8 5} \mathbf{5}^{\mathrm{T}}\right)$, a strain with the greatest enhancement of proliferation among lactobacilli examined; and L. helveticus JCM1120 $\left(\mathbf{L H} 1 \mathbf{1 2 0}^{\mathrm{T}}\right)$, a strain that suppressed proliferation to an extent comparable with LH2171. Figure 2 shows that LH2171 and $\mathrm{LH} 1120^{\mathrm{T}}$ inhibited the proliferation of MLN, PP, and SP cells when stimulated with antiCD3/CD28, whereas LG1131 ${ }^{\mathrm{T}}$ and $\mathrm{LC} 1185^{\mathrm{T}}$ did not inhibit the proliferation of any of the immune cells. When stimulated with LPS, LH2171 and LH1120 ${ }^{\mathrm{T}}$ inhibited the proliferation of the immune cells more significantly than LG1131 ${ }^{\mathrm{T}}$ and $\mathrm{LC} 1185^{\mathrm{T}}$.

\section{LH2171 Did Not Affect the Viability of Immune Cells}

We measured the number of viable immune cells when they were incubated with LH2171 to examine whether its antiproliferative potency could be attributed to a reduction in cell viability. Figure 3 shows that LH2171 did not significantly reduce the viability of MLN, PP, and SP cells compared with the control containing no LAB. The LG1131 ${ }^{\mathrm{T}}$ strain, which was used as a comparison and had no or less suppressive action on the anti-CD3/CD28- or LPS-induced immune cell proliferation compared with LH2171, also caused no significant changes in the viability of MLN and PP 


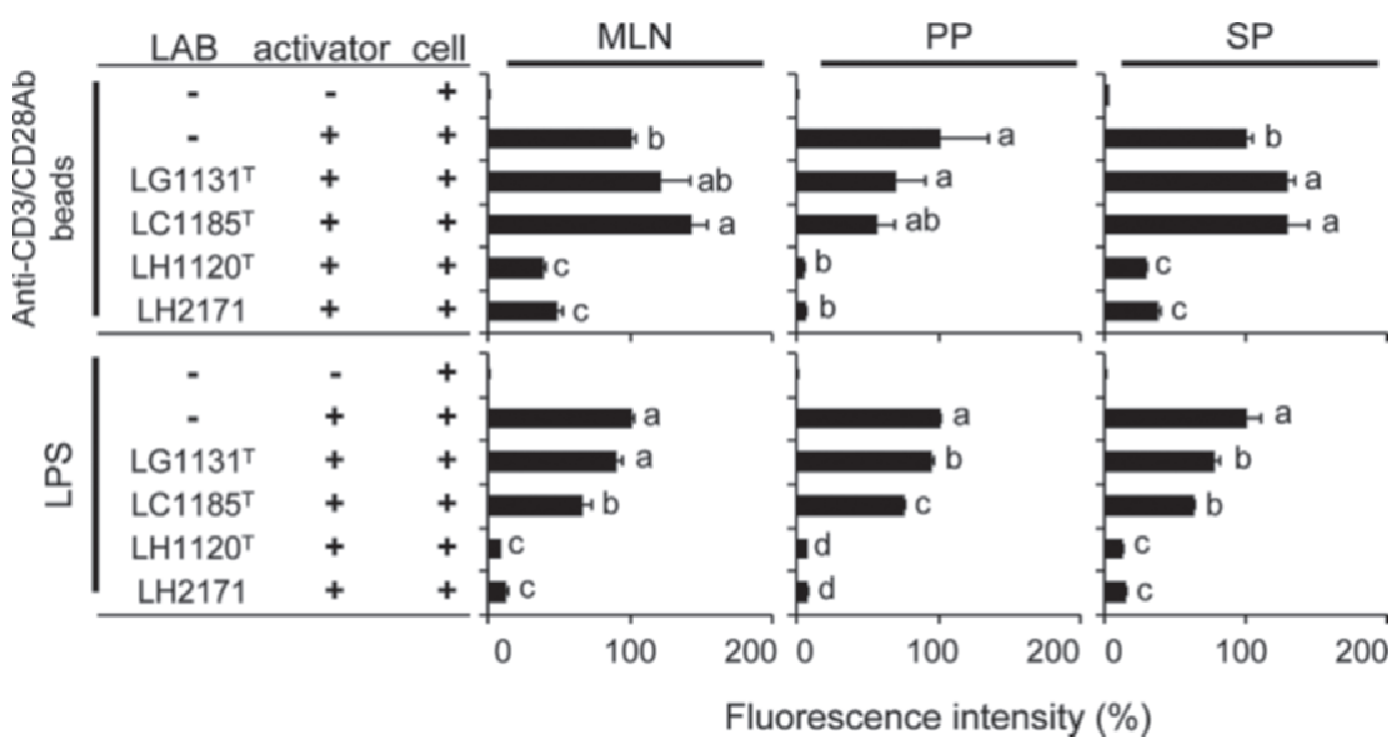

Figure 2. Effect of heat-treated lactic acid bacteria (LAB) on the proliferation of mesenteric lymph node (MLN), Peyer's patch (PP), and spleen (SP) cells stimulated with anti-CD3/CD28 antibody beads or LPS. Proliferation was represented as fluorescence intensity (\%), in which the control value obtained by the anti-CD3/CD28 or LPS stimulation alone was set to $100 \%$. Data are shown as means \pm SD (n $=3$ ). Statistical differences between the groups were analyzed using the Tukey-Kramer test and significant differences $(P<0.05)$ are represented by different letters $(\mathrm{a}-\mathrm{d}) . \mathrm{LG}_{1131^{\mathrm{T}}}=$ Lactobacillus gasseri $\mathrm{JCM} 1131^{\mathrm{T}} ; \mathrm{LC} 1185^{\mathrm{T}}=$ Lactobacillus crispatus $\mathrm{JCM} 1185^{\mathrm{T}} ;$ LH $1120^{\mathrm{T}}=$ Lactobacillus helveticus JCM1120 $;$ LH2171 = Lactobacillus helveticus SBT2171.

cells, except in SP cells in which LG1131 ${ }^{\mathrm{T}}$ significantly enhanced proliferation compared with the control.

\section{LH2171 Suppressed LPS-Stimulated IL-6 and IL-1 $\beta$ Production}

We examined whether LH2171 suppressed the production of proinflammatory cytokines (IL-6, IL-1 3 , and TNF- $\alpha$ ) in the culture supernatants of LPS-stimulated immune cells. Figure 4a shows that LH2171 suppressed IL-6 production of MLN, PP, and SP; by contrast, LG1131 ${ }^{\mathrm{T}}$, whose inhibitory action on immune cell proliferation was small compared with LH2171, had no suppressive effect on the production of IL-6. Figure 4b shows that LPS stimulation also induced IL-1 $\beta$ production of SP, and this induction was significantly inhibited by LH2171 and LG1131 ${ }^{\mathrm{T}}$, in which LH2171 showed a more significant inhibition compared with LG1131 ${ }^{\mathrm{T}}$. In PP and MLN, in contrast to SP, IL- $1 \beta$ was not induced by LPS stimulation (data not shown). Lactobacillus helveticus SBT2171 did not consistently regulate TNF- $\alpha$ production, and the levels also fluctuated between the 3 independent experiments (data not shown).

\section{DISCUSSION}

Several immunoregulatory actions of L. helveticus on mammalian cells have been reported, although the num-

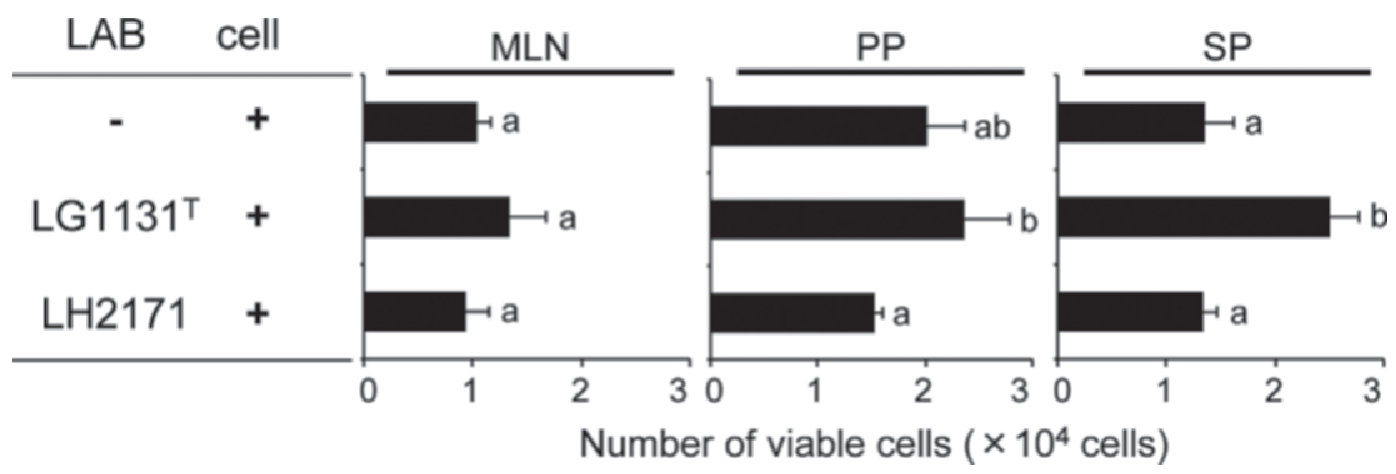

Figure 3. Effect of heat-treated lactic acid bacteria (LAB) on the viability of mesenteric lymph node (MLN), Peyer's patch (PP), and spleen (SP) cells. Viability was determined as the number of viable cells. Data are shown as means \pm SD $(n=3)$. Statistical differences between the groups were analyzed using the Tukey-Kramer test and significant differences $(P<0.05)$ are represented by different letters $(\mathrm{a}$ and $\mathrm{b})$. LG1131 ${ }^{\mathrm{T}}$ $=$ Lactobacillus gasseri $\mathrm{JCM} 1131^{\mathrm{T}}$; LH2171 = Lactobacillus helveticus $\mathrm{SBT} 2171$. 
a)

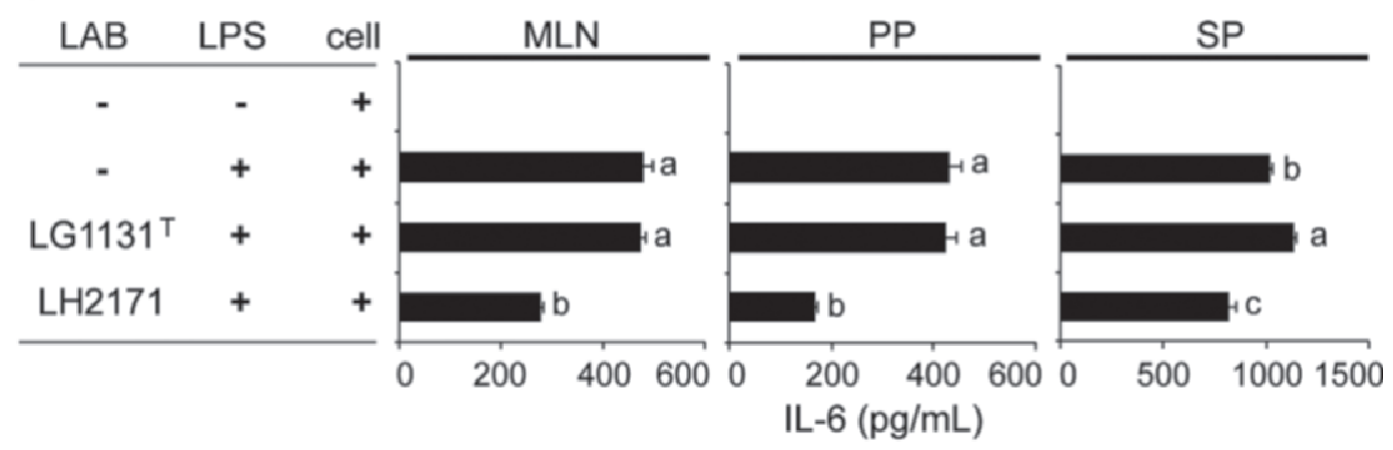

b)

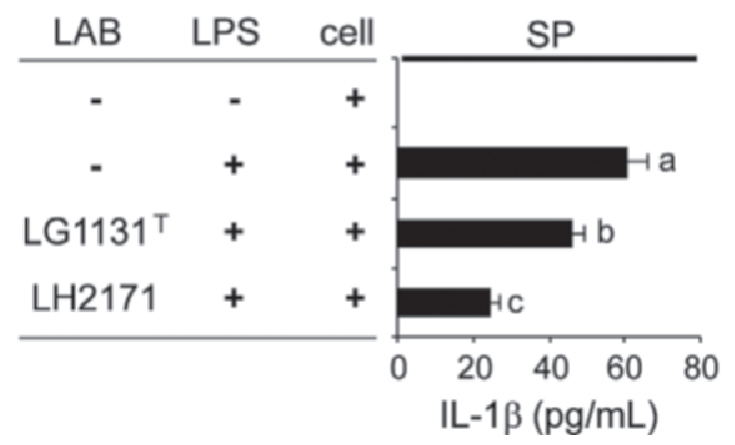

Figure 4. Effect of heat-treated lactic acid bacteria (LAB) on the proinflammatory cytokines IL-6 (a) and IL-1 $\beta$ (b) produced by LPSstimulated immune cells of mesenteric lymph nodes $(\mathrm{MLN})$, Peyer's patches (PP), and spleens (SP). Data are shown as means \pm SD $(\mathrm{n}=3)$. Statistical differences between the groups were analyzed using the Tukey-Kramer test and significant differences $(P<0.05)$ are represented by different letters $(\mathrm{a}-\mathrm{c}) . \mathrm{LG}_{1131^{\mathrm{T}}}=$ Lactobacillus gasseri $\mathrm{JCM} 1131^{\mathrm{T}} ;$ LH2171 = Lactobacillus helveticus SBT2171.

ber of publications is limited. Oral administration of $L$. helveticus cells inhibited the expression of proinflammatory cytokines and the activation of nuclear factor $\kappa \mathrm{B}$ in LPS-stimulated mouse peritoneal macrophages (Joo et al., 2012), and the production of IL-8, a chemokine involved in acute-phase inflammation, was reduced in human intestinal epithelial cells treated with fermented preparations containing L. helveticus (Wagar et al., 2009). The present study further examined the immunoregulatory actions of L. helveticus using heat-treated LH2171 bacterial cells and immune cells, including PP, MLN, and SP cells, and demonstrated significant suppressive activity on immune cell proliferation among 41 LAB strains of various species and on the production of several inflammatory cytokines.

A well-known mechanism of the suppressive action is cell death, including apoptosis: L. acidophilus strain L-92 inhibited antigen-stimulated $\mathrm{CD} 4^{+}$T-cell proliferation by inducing apoptosis (Kanzato et al., 2008). By contrast, LH2171 did not affect the viability of immune cells, indicating that it did not induce apoptosis but inhibited immune cell proliferation by a mechanism different from that of the L-92 strain.
Metabolites of LAB have been shown to suppress immune cell proliferation. Peluso et al. (2007) showed that live L. paracasei ssp. paracasei B21060 directly inhibited human $\mathrm{CD} 4^{+}$T-cell proliferation and those authors showed that lactic acid produced from live bacteria suppressed $\mathrm{CD} 4^{+}$T-cell proliferation. However, we used heat-killed bacteria, which did not produce lactic acid in the assay system, so LH2171 could not have inhibited proliferation by its metabolites.

The inhibitory effect of heat-killed bacteria on lymphocyte proliferation has been reported with L. gasseri OLL2809 by Yoshida et al. (2011), who showed that the inhibitory effect required RNA from strain OLL2809, suggesting that the suppressive effect occurred through the toll-like receptor 7 , a receptor for bacterial single-stranded RNA in mammalian cells. They also showed that bacterial cells and their RNA did not induce apoptosis, IL-10 secretion, or changes in the ratio of regulatory Foxp $3^{+}$cells in $\mathrm{CD} 4^{+} \mathrm{T}$ cells. Similarly, LH2171 did not induce IL-10 secretion or Foxp $3^{+}$cells (data not shown), both of which are essential factors in suppressing immune cell proliferation, suggesting that the mechanism by which LH2171 sup- 
pressed cell proliferation might be similar to that of strain OLL2809.

We then examined whether LH2171 suppressed IL-6, IL-1 $\beta$, and TNF- $\alpha$, which are proinflammatory cytokines whose production from immune cells is known to be strongly stimulated by LPS. Lipopolysaccharide is a critical factor in inflammatory disorders: intestinal overgrowth of Bacteroides, a group of gram-negative bacteria possessing LPS in its cellular components, induced severe intestinal inflammation in rats (Rath et al., 1999); colitis was less severe in mice lacking the gene for LPS recognition (Lps on mouse chromosome 4 ), which regulates the responsiveness to lipid A, compared with normal mice (Lange et al., 1996). The crucial role of these inflammatory cytokines is also well known; IL-6, IL-1 $\beta$, and TNF- $\alpha$ were more strongly induced in mice with colitis than in control mice (Philippe et al., 2011). The present study showed that LH2171 significantly suppressed IL-6 production in LPS-stimulated MLN, PP, and SP. Lactobacillus helveticus SBT2171 also significantly suppressed IL-1 $\beta$ production of LPSstimulated SP. However, such suppression was not observed with $\mathrm{LG} 1131^{\mathrm{T}}$, which was used for comparison due to its taxonomic proximity to L. helveticus in the Lactobacillus genus, according to the analysis of their 16s rRNA (Felis and Dellaglio, 2007), suggesting the importance of strain LH2171 among lactobacilli.

We consider the suppression of IL-6 to be the most important issue, because IL-6 is secreted from lymphocytes in inflammatory diseases, such as IBD and RA; patients with IBD and RA produced more IL-6 than control patients (Reimund et al., 1996; Hosokawa et al., 1999; Hashizume and Mihara, 2011; Oranskiy et al., 2012) and IL6-gene-disrupted mice were resistant to dextran sulfate sodium-induced colitis (Suzuki et al., 2001) and RA (Alonzi et al., 1998). Some LAB and probiotic bacteria have also been reported to downregulate IL-6 production and alleviate inflammatory diseases (Matsumoto et al., 2005; Fitzpatrick et al., 2008). Lactobacillus casei strain Shirota downregulated IL-6 in the lamina propria mononuclear cells in the large intestine and improved murine chronic colitis (Matsumoto et al., 2005). In the present study, LH2171 exhibited significant suppression of IL-6 from MLN, PP, and SP in vitro, which warrants further examination of the effect in vivo in the future.

Lactobacillus helveticus SBT2171 significantly reduced cell proliferation and IL- 6 and IL- $1 \beta$ production. The results were consistent between the independent experiments. In contrast, TNF- $\alpha$ was not consistently regulated between the experiments (data not shown). Thus, the reduction in immune cell proliferation was correlated only with the reduction in IL- 6 and IL-1 $\beta$ production, but not with TNF- $\alpha$. This also suggests that reduced cell proliferation per se might not be a direct cause of decreased cytokine production. Pathways through which LH2171 inhibits cell proliferation and cytokine production remain to be investigated.

\section{CONCLUSIONS}

Lactobacillus helveticus SBT2171 significantly suppressed the proliferation of immune cells of MLN, PP, and SP stimulated with anti-CD3/CD28 antibodies and LPS. Lactobacillus helveticus SBT2171 also reduced the production of LPS-stimulated proinflammatory cytokines (IL-6 from MLN, PP, and SP; IL-1 $\beta$ from $\mathrm{SP})$. These regulatory effects on immune cells were not due to cytotoxicity, suggesting that LH2171 is a dairy Lactobacillus strain with beneficial immunoregulatory properties.

\section{ACKNOWLEDGMENTS}

We are grateful to Tomohiro Moriya and Kurumi Takagi (both of Milk Science Research Institute, Megmilk Snow Brand Co. Ltd., Saitama, Japan) for their skillful collaboration.

\section{REFERENCES}

Alonzi, T., E. Fattori, D. Lazzaro, P. Costa, L. Probert, G. Kollias, F. De Benedetti, V. Poli, and G. Ciliberto. 1998. Interleukin 6 is required for the development of collagen-induced arthritis. J. Exp. Med. 187:461-468.

Atreya, R.. J. Mudter, S. Finotto, J. Müllberg, T. Jostock, S. Wirtz, M. Schütz, B. Bartsch, M. Holtmann, C. Becker, D. Strand, J. Czaja, J. F. Schlaak, H. A. Lehr, F. Autschbach, G. Schürmann, N. Nishimoto, K. Yoshizaki, H. Ito, T. Kishimoto, P. R. Galle, S. Rose-John, and M. F. Neurath. 2000. Blockade of interleukin 6 trans signaling suppresses T-cell resistance against apoptosis in chronic intestinal inflammation: Evidence in Crohn disease and experimental colitis in vivo. Nat. Med. 6:583-588.

Felis, G. E., and F. Dellaglio. 2007. Taxonomy of lactobacilli and bifidobacteria. Curr. Issues Intest. Microbiol. 8:44-61.

Fitzpatrick, L. R., J. Small, R. A. Hoerr, E. F. Bostwick, L. Maines, and W. A. Koltun. 2008. In vitro and in vivo effects of the probiotic Escherichia coli strain M-17: Immunomodulation and attenuation of murine colitis. Br. J. Nutr. 100:530-541.

Hashizume, M., and M. Mihara. 2011. The roles of interleukin-6 in the pathogenesis of rheumatoid arthritis. Arthritis 2011:765624.

Hosokawa, T., K. Kusugami, K. Ina, T. Ando, M. Shinoda, A. Imada, M. Ohsuga, T. Sakai, T. Matsuura, K. Ito, and K. Kaneshiro. 1999. Interleukin-6 and soluble interleukin-6 receptor in the colonic mucosa of inflammatory bowel disease. J. Gastroenterol. Hepatol. 14:987-996.

Hosoya, T., A. Ogawa, F. Sakai, and Y. Kadooka. 2012. A cheese-containing diet modulates immune responses and alleviates dextran sodium sulfate-induced colitis in mice. J. Dairy Sci. 95:2810-2818.

Ibrahim, F., S. Ruvio, L. Granlund, S. Salminen, M. Viitanen, and A. C. Ouwehand. 2010. Probiotics and immunosenescence: Cheese as a carrier. FEMS Immunol. Med. Microbiol. 59:53-59.

Joo, H.-M., K.-A. Kim, K.-S. Myoung, Y.-T. Ahn, J.-H. Lee, C.-S Huh, M. J. Han, and D.-H. Kim. 2012. Lactobacillus helveticus HY7801 ameliorates vulvovaginal candidiasis in mice by inhibiting fungal growth and NF- $\kappa \mathrm{B}$ activation. Int. Immunopharmacol. 14:39-46. 
Kanzato, H., S. Fujiwara, W. Ise, S. Kaminogawa, R. Sato, and S. Hachimura. 2008. Lactobacillus acidophilus strain L-92 induces apoptosis of antigen-stimulated $\mathrm{T}$ cells by modulating dendritic cell function. Immunobiology 213:399-408.

Lange, S., D. S. Delbro, E. Jennische, and I. Mattsby-Baltzer. 1996. The role of the Lps gene in experimental ulcerative colitis in mice. APMIS 104:823-833.

Lee, H.-S., S.-Y. Han, E.-A. Bae, C.-S. Huh, Y.-T. Ahn, J.-H. Lee, and D.-H. Kim. 2008. Lactic acid bacteria inhibit proinflammatory cytokine expression and bacterial glycosaminoglycan degradation activity in dextran sulfate sodium-induced colitic mice. Int. Immunopharmacol. 8:574-580.

Lollo, P. C. B., A. G. Cruz, P. N. Morato, C. S. Moura, L. B. Carvalho-Silva, C. A. F. Oliveira, J. A. F. Faria, and J. Amaya-Farfan. 2012. Probiotic cheese attenuates exercise-induced immune suppression in Wistar rats. J. Dairy Sci. 95:3549-3558.

Matsumoto, S., T. Hara, T. Hori, K. Mitsuyama, M. Nagaoka, N. Tomiyasu, A. Suzuki, and M. Sata. 2005. Probiotic Lactobacillusinduced improvement in murine chronic inflammatory bowel disease is associated with the down-regulation of pro-inflammatory cytokines in lamina propria mononuclear cells. Clin. Exp. Immunol. 140:417-426.

NRC. 1996. Guide for the Care and Use of Laboratory Animals. The National Academies Press, Washington, DC.

Oranskiy, S. P., L. N. Yeliseyeva, A. V. Tsanaeva, and N. V. Zaytseva. 2012. Body composition and serum levels of adiponectin, vascular endothelial growth factor, and interleukin-6 in patients with rheumatoid arthritis. Croat. Med. J. 53:350-356.

Peluso, I., D. Fina, R. Caruso, C. Stolfi, F. Caprioli, M. C. Fantini, G. Caspani, E. Grossi, L. D. Iorio, F. M. Paone, F. Pallone, and G. Monteleone. 2007. Lactobacillus paracasei $\mathrm{ssp}$. paracasei B21060 suppresses human T-cell proliferation. Infect. Immun. 75:17301737.
Philippe, D., E. Heupel, S. Blum-Sperisen, and C. U. Riedel. 2011. Treatment with Bifidobacterium bifidum 17 partially protects mice from Th1-driven inflammation in a chemically induced model of colitis. Int. J. Food Microbiol. 149:45-49.

Rath, H. C., J. S. Ikeda, H. J. Linde, J. Schölmerich, K. H. Wilson, and R. B. Sartor. 1999. Varying cecal bacterial loads influences colitis and gastritis in HLA-B27 transgenic rats. Gastroenterology 116:310-319.

Reimund, J. M., C. Wittersheim, S. Dumont, C. D. Muller, R. Baumann, P. Poindron, and B. Duclos. 1996. Mucosal inflammatory cytokine production by intestinal biopsies in patients with ulcerative colitis and Crohn's disease. J. Clin. Immunol. 16:144-150.

Suzuki, A., T. Hanada, K. Mitsuyama, T. Yoshida, S. Kamizono, T. Hoshino, M. Kubo, A. Yamashita, M. Okabe, K. Takeda, S. Akira, S. Matsumoto, A. Toyonaga, M. Sata, and A. Yoshimura. 2001. CIS3/SOCS3/SSI3 plays a negative regulatory role in STAT3 activation and intestinal inflammation. J. Exp. Med. 193:471-481.

Tan, P. S. T., M. Sasaki, B. W. Bosman, and T. Iwasaki. 1995. Purification and characterization of a dipeptidase from Lactobacillus helveticus SBT 2171. Appl. Environ. Microbiol. 61:3430-3435.

Wagar, L. E., C. P. Champagne, N. D. Buckley, Y. Raymond, and J. M. Green-Johnson. 2009. Immunomodulatory properties of fermented soy and dairy milks prepared with lactic acid bacteria. J. Food Sci. 74:M423-M430.

Yamamoto, M., K. Yoshizaki, T. Kishimoto, and H. Ito. 2000. IL-6 is required for the development of Th1 cell-mediated murine colitis. J. Immunol. 164:4878-4882.

Yoshida, A., K. Yamada, Y. Yamazaki, T. Sashihara, S. Ikegami, M. Shimizu, and M. Totsuka. 2011. Lactobacillus gasseri OLL2809 and its RNA suppress proliferation of $\mathrm{CD}^{+} \mathrm{T}$ cells through a MyD88-dependent signalling pathway. Immunology 133:442-451. 